\title{
EFFICACY OF CHAIR BASED EXERCISES TO IMPROVE SELF REPORTED SLEEP PROBLEMS AND DEPRESSION AMONG INSTITUTIONALISED ELDERLY
}

Sheetal Aurangabadkar *1, Medha Deo ${ }^{2}$.

${ }^{* 1}$ MPTh Community Medical sciences, Asst. professor, Terna College of Physiotherapy, Nerul, Navi Mumbai, India.

${ }^{2}$ MPT. Musculoskeletal Sciences, Principal \& Professor, Terna College of Physiotherapy, Nerul, Navi Mumbai, India.

\section{ABSTRACT}

Background: Poor sleep quality and depression along with physiological changes due to ageing contribute to increased incidences of falls.It has been observed that among most of the elderly residents these problems remain untreated and studies have shown almost eighty five percentage of this population rely on antidepressants and sedatives as a treatment of choice. But these medications can have deleterious side effects like day time confusion, drowsiness and falls. Physical exercises in different modes like resisted exercises or Tai Chai have shown to improve sleep quality and depression. But most of these exercises are done in standing or unaided and they can be difficult or impossible for frail elderly due to their co-morbidity and increased risk of falling.

Methodology: Permission to carry out the study was taken from concerned authorities of old age homes.Written consent was taken from participants.Thirty subjects aged sixty five years and above were recruited in the study from the old age homes, Navi Mumbai. The participants were screened and pre-test score for depression and sleep quality were taken on Pittsburgh Sleep quality index and Geriatric depression scale. A structured group ,chair based exercises was undertaken and supervised by the physiotherapist,twice in a week for ten weeks.The exercises included were warm up, free mobility exercises for upper and lower limbs,breathing exercises and cool down for about forty five minutes. After completion of ten weeks post test score for outcome measures were noted and results were analysed.

Results: Statistical analysis was done using Wilcoxon signed rank test for Pittsburg Sleep Quality Index and Geriatric Depression Scale. The Global Score of sleep quality scale showed improvement post-test value of 9.5 from $12.5, z$ value $4.230, p$ value less than 0.001 .The post test for depression improved to 12 from pre-test score of $17, z$ value $4.639, p$ value less than 0.001 .The study was single blinded to reduce bias.

Conclusion: Chair based exercises can be considered as simple and effective exercises to improve poor sleep quality and depression among institutionalized elderly.

KEY WORDS: Chair Based Exercises, Insomnia, Depression.

Address for correspondence: Dr. Sheetal Aurangabadkar. (MPTh Community Medical sciences.) Asst. professor. Terna College of Physiotherapy, Nerul, Navi Mumbai, India.

E-Mail:coolchimi@gmail.com

Access this Article online

Quick Response code

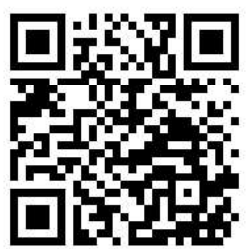

DOI: $10.16965 /$ ijpr.2019.202

\begin{tabular}{|c|c|c|}
\hline \multicolumn{3}{|c|}{ Journal Information } \\
\hline \multicolumn{3}{|c|}{$\begin{array}{l}\text { International Journal of Physiotherapy and Research } \\
\begin{array}{l}\text { ICV for 2016 ISSN (E) 2321-1822 | ISSN (P) 2321-8975 }\end{array}\end{array}$} \\
\hline \multicolumn{3}{|c|}{ Article Information } \\
\hline $\begin{array}{l}\text { Received: } 21 \text { Nov } 2019 \\
\text { Peer Review: } 21 \text { Nov } 2019 \\
\text { Revised: None }\end{array}$ & $\begin{array}{l}\text { Accepted: } 12 \text { Dec } \\
\text { Published (O): } 11 \\
\text { Published (P): } 11\end{array}$ & $\begin{array}{l}9 \\
2020 \\
2020\end{array}$ \\
\hline
\end{tabular}

being themost common sleep disorder. According to International Classification of sleep disorders, third edition, Insomnia is defined as
Sleep problems especially Insomnia is highly prevalent in geriatric population, insomnia 
acute or chronic sleep disorder characterized by difficulty in initiating or maintaining sleep, early morning awakening that occur at a minimum of three nights per week, for three months and are associated with significant daytime consequences [1]. Prevalence of Insomnia increases with age, higher prevalence of insomnia among older adults is thought to be consequence of physical and mental co morbidity rather than consequences of ageing itself [2]. Negative consequences of Insomnia in late life include decreased quality of life, risks for falls, psychological and physical difficulties,economic and social costs, risks for nursing home placement and mortality [3].

Insomnia is classified as either primary or co morbid. Primary insomnia implies that no other cause of sleep disturbance has been identified. Co morbid insomnia is more common and is often associated with psychiatric disorders (depression, anxiety), substance use disorders, medical disorders like cardio pulmonary disorders, neurologic disorders, medications. Prevalence of Insomnia increases with age and unfortunately less than fifteen percent of patients with Insomnia receive treatment or consult health care provider [4]. Untreated Insomnia leads to fatigue, depression, cognitive impairments, depression and increased risk of falls. Studies have shown that there is twenty three percent increased risk of depression in patients with untreated insomnia [5].

Most elderly people rely on antidepressants and sedatives as a treatment of choice but these medications can have side effects like drowsiness, confusion and increased risk of falls. Exercises have shown to have several health benefits but most elderly people engage in less exercise with advancing age. Research has shown that Tai chi and resisted exercises help to improve sleep quality and depression. But most of these exercises are done in standing position and are difficult to frail elderly due to their co morbidities. Thus Chair Based Exercises (CBE) can be considered as pragmatic way of encouraging exercises for frail elderly population.

Chair Based exercises are defined as primarily seated, structured, progressive exercise programme which uses chair to provide stability and is given by instructors that are skilled and trained to work with frail elderly [6].

AIM: To study the effects of structured CBE on self reported sleep quality and depression among institutionalized elderly population .

OBJECTIVES: To study the effects of structured CBE onself reported sleep problems on Pittsburg Sleep Quality Index (PSQI)

To study the effects of structured CBE on self reported depression on Geriatric Depression Scale (GDS)

\section{MATERIALS AND METHODS}

- A sturdy chair with arm rest

- Evaluation Proforma

Pittsburg Sleep Quality Index(PSQI) -The Pittsburg Sleep Quality Index is a self rated questionnaire which assesses sleep quality and disturbance over one month interval. Nineteen individual items create seven component score :subjective sleep quality, latency, sleep duration, habitual sleep efficiency, sleep disturbances, use of sleep medications and day time dysfunction. The sum of scores of these seven components yield one global score.A global score greater than five yielded diagnostic sensitivity of $89.6 \%$ and specificity of $86.5 \%$ in distinguishing good and poor sleepers [7].

Geriatric Depression Scale(long form)-It is thirty item self report assessment used to identify depression in elderly. Here questions are answered yes or no. Range of score is 0 to 9 as normal,10 to 19 as mildly depressed and 20 to 30 as severly depressed. It has $92 \%$ sensitivity and $89 \%$ specificity when evaluated against diagnostic criteria [8].

\section{Inclusion criteria -}

- Institutionalised elderly , 65 years and above

- Both males and females

- Relative sedentary individuals.

- With or without assistive device.

\section{Exclusion criteria}

- Those with severe cognitive decline

- Any unstable medical condition where exercises are contra indicated

- Those who were voluntarily not ready to participate 
Table 1: Age group \& Sex wise distribution of Geriatric Patients.

\begin{tabular}{|c|c|c|c|c|c|c|}
\hline Age Group & \multicolumn{2}{|c|}{ Female } & \multicolumn{2}{c|}{ Male } & \multicolumn{2}{c|}{ Total } \\
\hline & $\mathbf{N}$ & $\mathbf{\%}$ & $\mathbf{N}$ & $\mathbf{\%}$ & $\mathbf{N}$ & $\mathbf{\%}$ \\
\hline $\mathbf{6 5 - 7 4}$ & $\mathbf{7}$ & 70 & 3 & 30 & 10 & 100 \\
\hline $\mathbf{7 5 - 8 4}$ & 11 & 78.6 & 3 & 21.4 & 14 & 100 \\
\hline $\mathbf{8 5}-\mathbf{9 4}$ & 6 & 100 & 0 & 0 & 6 & 100 \\
\hline Total & 24 & 80 & 6 & 20 & 30 & 100 \\
\hline
\end{tabular}

Age group of Geriatric Patients

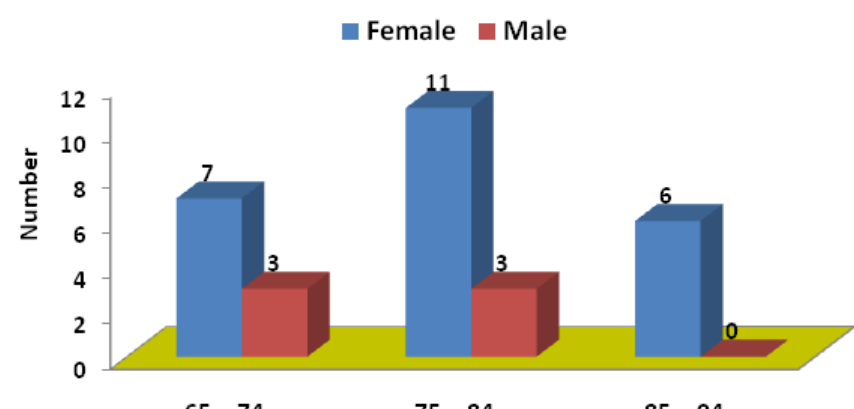

$65-74 \quad 75-84 \quad 85-94$

Age group (yrs)

\begin{tabular}{|c|c|c|c|c|c|}
\hline Parameters & \multicolumn{2}{|c|}{ Median Score } & \multicolumn{2}{|c|}{$\begin{array}{c}\text { Wilcoxon Signed rank } \\
\text { test }\end{array}$} & $\begin{array}{c}\text { Significant at } \\
\text { 5\% level }\end{array}$ \\
\hline & Pre Test & Post Test & Z -Value & P-Value & \\
\hline Sleep Quality & 2 & 1 & 4.899 & $<0.001$ & Yes \\
\hline Sleep Latency & 2 & 1 & 3.742 & $<0.001$ & Yes \\
\hline Sleep Duration & 2 & 2 & 1.015 & 0.31 & No \\
\hline $\begin{array}{c}\text { Habitual Sleep } \\
\text { Efficiency }\end{array}$ & 2 & 2 & 2.236 & 0.025 & Yes \\
\hline $\begin{array}{c}\text { Step Disturbances } \\
\text { Day time } \\
\text { disfunction }\end{array}$ & 2 & 2 & 0.66 & 0.509 & No \\
\hline $\begin{array}{c}\text { Sleeping } \\
\text { Medication }\end{array}$ & 0 & 0 & 0 & 1 & No \\
\hline GS(21) & 12.5 & 9.5 & 4.23 & $<0.001$ & Yes \\
\hline GDS & 17 & 12 & 4.639 & $<0.001$ & Yes \\
\hline
\end{tabular}

Table 2:Table shows the median and level of significance of outcome measures. The Global score of Pittsburg Sleep Quality index showed significant improvement post test with $z$ value 4.230 and $p$ value $<0.01$.

Table 3: Sleep Quality.

\begin{tabular}{|c|c|c|c|c|c|c|}
\hline Sleep Quality & \multicolumn{2}{|c|}{ Pre Test } & \multicolumn{2}{c|}{ Post Test } & \multicolumn{2}{c|}{ Total } \\
\hline & N & $\%$ & N & $\%$ & N & $\%$ \\
\hline Very Good & 0 & 0 & 3 & 10 & 3 & 5 \\
\hline Fairly Good & 6 & 20 & 15 & 50 & 21 & 35 \\
\hline Fairly Bad & 12 & 40 & 9 & 30 & 21 & 35 \\
\hline Very Bad & 12 & 40 & 3 & 10 & 15 & 25 \\
\hline Total & 30 & 100 & 30 & 100 & 60 & 100 \\
\hline
\end{tabular}

Fig.3: Shows the pre test and post test values of the sleep quality of the participants on PSQIby using Wilcoxor signed rank test.The post test value showed significance with $z$ value 4.89 and $p$ value $<0.01$.
Sleep Quality of Geriatric Patients - Pre Test ${ }_{50.0 \%}$ Post Test

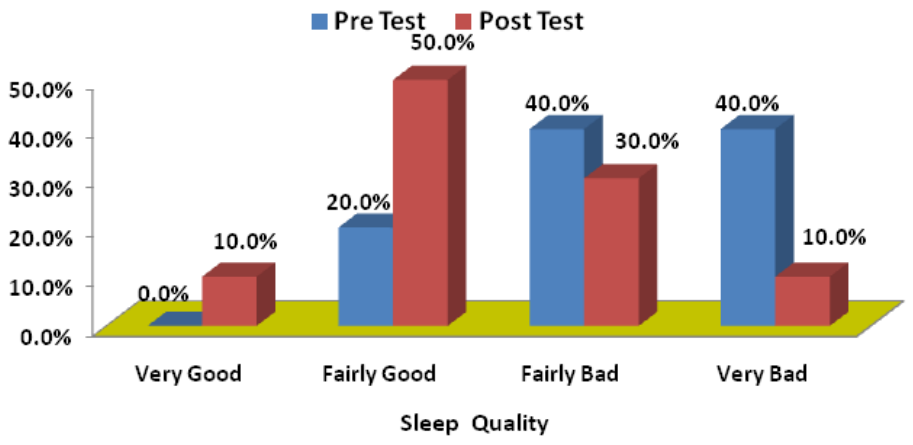


Table 4:Sleep Latency.

\begin{tabular}{|c|c|c|c|c|c|c|}
\hline Sleep Latency & \multicolumn{2}{|c|}{ Pre Test } & \multicolumn{2}{c|}{ Post Test } & \multicolumn{2}{c|}{ Total } \\
\hline & $\mathbf{N}$ & $\mathbf{\%}$ & $\mathbf{N}$ & $\mathbf{\%}$ & $\mathbf{N}$ & $\mathbf{\%}$ \\
\hline $\mathbf{5} \mathbf{1 5}$ minutes & 0 & 0 & 0 & 0 & 0 & 0 \\
\hline $\mathbf{1 6}-\mathbf{3 0}$ minutes & 5 & 16.7 & 16 & 53.3 & 21 & 35 \\
\hline $\mathbf{3 1 - 6 0}$ minutes & 17 & 56.7 & 9 & 30 & 26 & 43.3 \\
\hline $\mathbf{2 6 0}$ minutes & 8 & 26.7 & 5 & 16.7 & 13 & 21.7 \\
\hline Total & 30 & 100 & 30 & 100 & 60 & 100 \\
\hline
\end{tabular}

Sleep Latency of Geriatric Patients

are Test $\quad$ Post Test

Fig. 4: Shows the pre and post test values of sleep latency. There was improvement on Wilcoxon signed rank test with $Z$ value 3.742 and $p$ value $<0.01$.

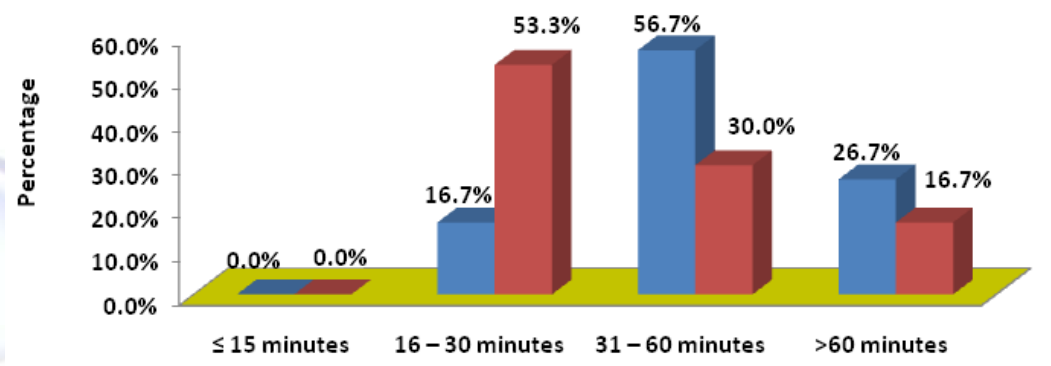

Table 5:Sleep Duration.

\begin{tabular}{|c|c|c|c|c|c|c|}
\hline \multicolumn{1}{|c|}{ Sleep Latency } \\
\hline Sleep Duration & \multicolumn{2}{|c|}{ Pre Test } & \multicolumn{2}{c|}{ Post Test } & \multicolumn{2}{c|}{ Total } \\
\hline & $\mathbf{N}$ & $\mathbf{\%}$ & $\mathbf{N}$ & $\mathbf{\%}$ & $\mathbf{N}$ & $\%$ \\
\hline $\mathbf{7}$ hours & 0 & 0 & 0 & 0 & 0 & 0 \\
\hline $\mathbf{6 - 7}$ hours & 6 & 20 & 9 & 30 & 15 & 25 \\
\hline $\mathbf{5 - 6}$ hours & 14 & 46.7 & 14 & 46.7 & 28 & 46.7 \\
\hline$<5$ hours & 10 & 33.3 & 7 & 23.3 & 17 & 28.3 \\
\hline Total & 30 & 100 & 30 & 100 & 60 & 100 \\
\hline
\end{tabular}

Sleep Duration of Geriatric Patients - Pre Test $\quad$ Post Test

Fig.5: Shows the pre and post values of sleep duration. There was no improvement in post test value as $z$ value was 1.015 and $p$ value was 0.310 on Wilcoxon signed rank test.

Table 6: Habitual Sleep Efficiency.

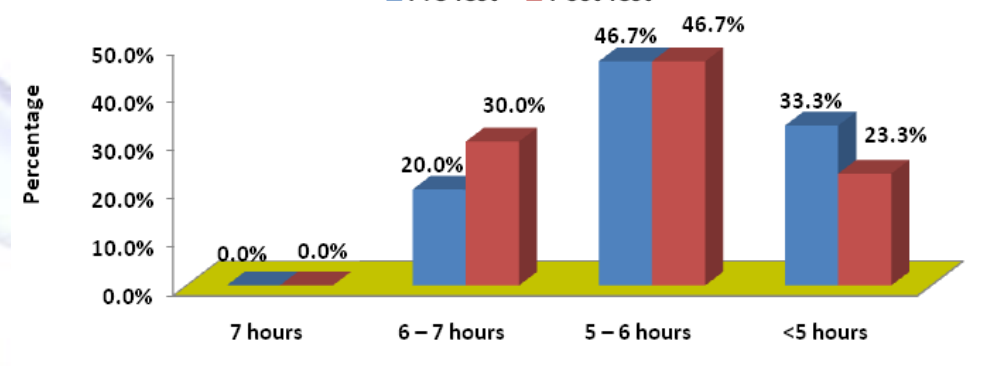

\begin{tabular}{|c|c|c|c|c|c|c|}
\hline $\begin{array}{c}\text { Habitual Sleep } \\
\text { Efficiency }\end{array}$ & \multicolumn{2}{|c|}{ Pre Test } & \multicolumn{2}{c|}{ Post Test } & \multicolumn{2}{c|}{ Total } \\
\hline & $\mathbf{N}$ & $\%$ & $\mathbf{N}$ & $\%$ & $\mathbf{N}$ & $\%$ \\
\hline $\mathbf{2 8 5 \%}$ & 1 & 3.3 & 1 & 3.3 & 2 & 3.3 \\
\hline $\mathbf{7 5 - 8 4} \%$ & 2 & 6.7 & 3 & 10 & 5 & 8.3 \\
\hline $\mathbf{6 5 - 7 4 \%}$ & 15 & 50 & 18 & 60 & 33 & 55 \\
\hline$<\mathbf{6 5 \%}$ & 12 & 40 & 8 & 26.7 & 20 & 33.3 \\
\hline Total & 30 & 100 & 30 & 100 & 60 & 100 \\
\hline
\end{tabular}

Habitual Sleep Efficiency of Geriatric Patients - Pre Test Post Test

Fig.6: It shows there was improvement in Habitual sleep efficiency with $z$ value 2.236 and $p$ value 0.025 of the post test values.

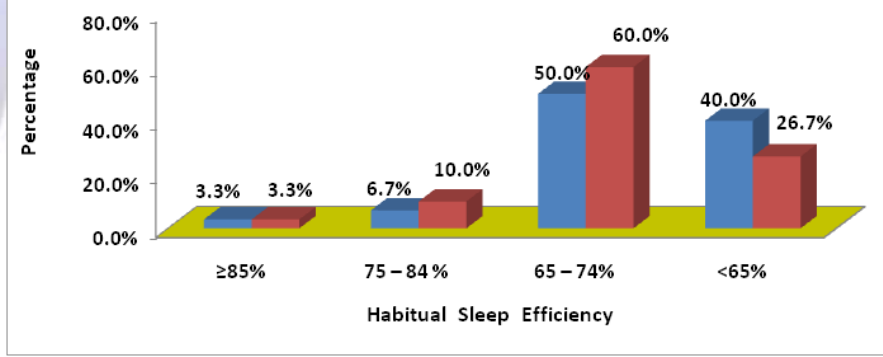


Table 7: Step Disturbances.

\begin{tabular}{|c|c|c|c|c|c|c|}
\hline $\begin{array}{c}\text { Step } \\
\text { Disturbances }\end{array}$ & \multicolumn{2}{|c|}{ Pre Test } & \multicolumn{2}{c|}{ Post Test } & \multicolumn{2}{c|}{ Total } \\
\hline & $\mathbf{N}$ & $\%$ & $\mathbf{N}$ & $\%$ & $\mathbf{N}$ & $\%$ \\
\hline $\mathbf{0}$ & 0 & 0 & 1 & 3.3 & 1 & 1.7 \\
\hline $\mathbf{1 - 9}$ & 9 & 30 & 7 & 23.3 & 16 & 26.7 \\
\hline $\mathbf{1 0 - 1 8}$ & 17 & 56.7 & 15 & 50 & 32 & 53.3 \\
\hline $\mathbf{1 9 - 2 7}$ & 4 & 13.3 & 7 & 23.3 & 11 & 18.3 \\
\hline Total & 30 & 100 & 30 & 100 & 60 & 100 \\
\hline
\end{tabular}

Fig. 7: Shows there was no improvement with respect to sleep disturbances with $z$ value 0.660 and $p$ value 0.509 after the intervention.

Fig. 8: In the study participants were not taking any sleep medications.

Table 8: Sleeping Medication.

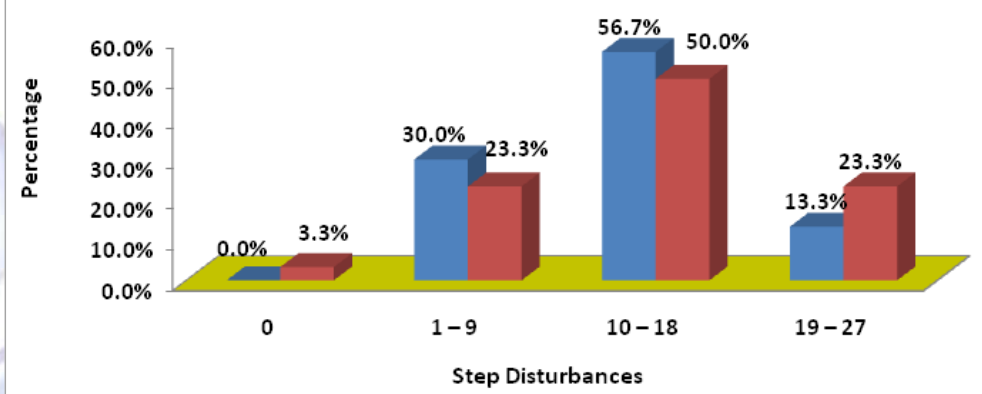

\begin{tabular}{|c|c|c|c|c|c|c|}
\hline $\begin{array}{c}\text { Sleeping } \\
\text { Medication }\end{array}$ & \multicolumn{2}{|c|}{ Pre Test } & \multicolumn{2}{c|}{ Post Test } & \multicolumn{2}{c|}{ Total } \\
\hline $\begin{array}{c}\text { Not during the } \\
\text { past month }\end{array}$ & 30 & 100 & 30 & 100 & 60 & 100 \\
\hline $\begin{array}{c}\text { Less than once a } \\
\text { week }\end{array}$ & 0 & 0 & 0 & 0 & 0 & 0 \\
\hline $\begin{array}{c}\text { Once or twice a } \\
\text { week }\end{array}$ & 0 & 0 & 0 & 0 & 0 & 0 \\
\hline $\begin{array}{c}\text { Three or more } \\
\text { times a week }\end{array}$ & 0 & 0 & 0 & 0 & 0 & 0 \\
\hline Total & 30 & 100 & 30 & 100 & 60 & 100 \\
\hline
\end{tabular}

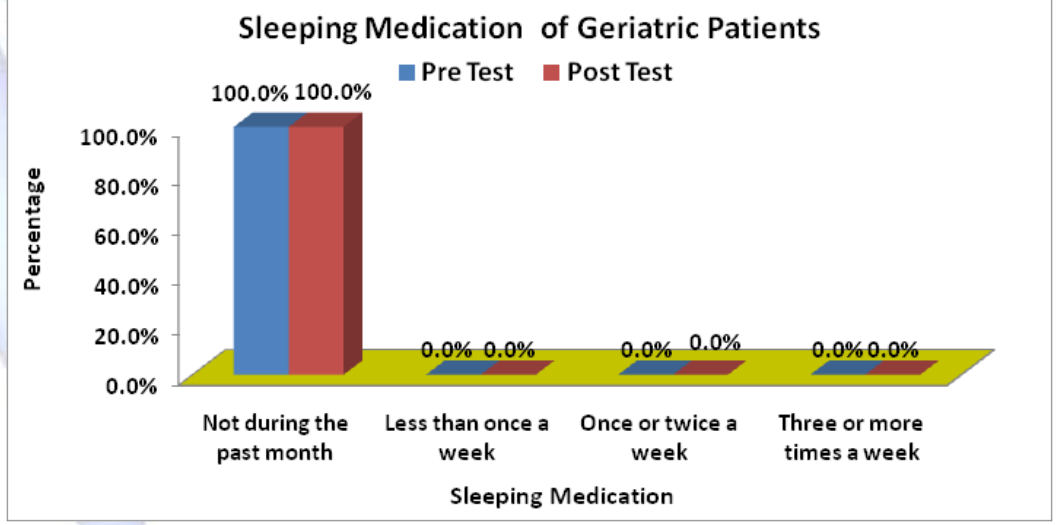

Table 9: Day time dysfunction.

\begin{tabular}{|c|c|c|c|c|c|c|}
\hline Day time dysfunction & \multicolumn{2}{|c|}{ Pre Test } & \multicolumn{2}{c|}{ Post Test } & \multicolumn{2}{c|}{ Total } \\
\hline & $\mathbf{N}$ & $\%$ & $\mathbf{N}$ & $\%$ & $\mathbf{N}$ & $\%$ \\
\hline Never & 0 & 0 & 0 & 0 & 0 & 0 \\
\hline Once or twice & 9 & 30 & 21 & 70 & 30 & 50 \\
\hline $\begin{array}{c}\text { Once or twice each } \\
\text { week }\end{array}$ & 20 & 66.7 & 9 & 30 & 29 & 48.3 \\
\hline $\begin{array}{c}\text { Three or more times } \\
\text { each week }\end{array}$ & 1 & 3.3 & 0 & 0 & 1 & 1.7 \\
\hline Total & 30 & 100 & 30 & 100 & 60 & 100 \\
\hline
\end{tabular}


Fig.9: There was improvement in day time functioning of the participants with $z$ value 3.606 and $p$ value $<0.001$.

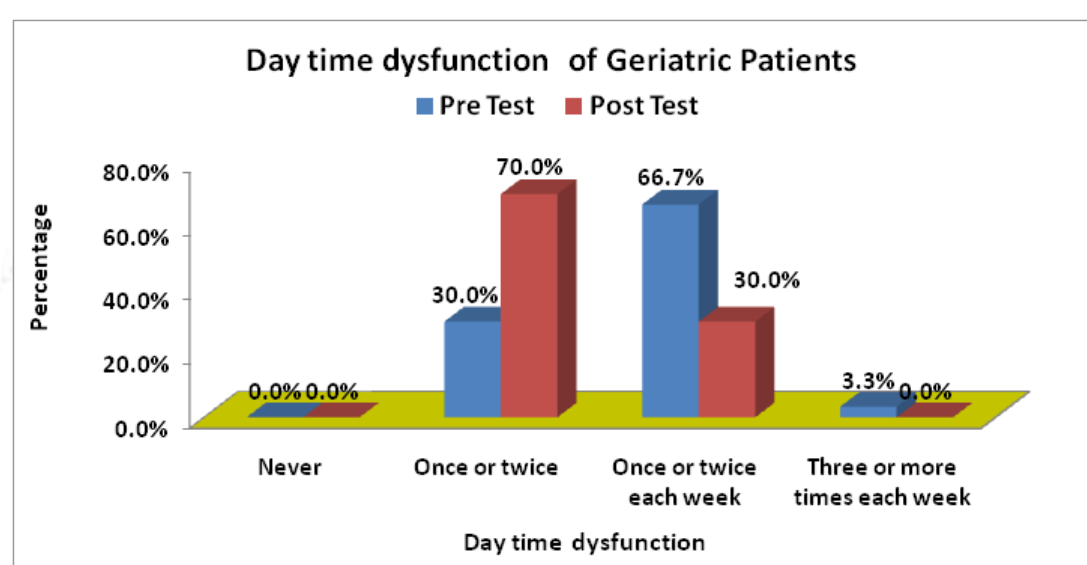

Permission to carry out the study was taken from ethical committee and authorities of oldage home.Consent was taken from participants and information about the study programme was given to them.Thirty subjects aged 65 years and above were recruited from two oldage homes, Navi Mumbai. The participants were screened and pre test score for sleep quality on PSQI and depression on GDS were taken. A structured CBE group exercises were given including warm up, free mobility exercises, breathing exercises, laughter exercises and cool down period for about 45 minutes, twice a week for about ten weeks.After completion of ten weeks, post test score were noted and results were analysed. To reduce experimental bias, first level blinding procedure was adopted.

Exercises given were - warm up -chair march, arm swings, arm reach, leg extension Mobility exercises - neck exercises, shoulder circles, knee and hip exercises, foot tapping, co-ordination exercises, hand exercises, bicep curl , knee taps, leg extend, sit to stand, leg circles.

Laughing exercises -Initially they were shown a video demonstrating laughing exercises. They were instructed to relax the facial muscles, clap their hands, say hello to each other, laugh aloud clapping their hands .Laughing while pronouncing the vowels was also encouraged. The group was given simple breathing exercises.

Statistical Analysis: The data was collected and analysed by using SPSS version 20.0.ThePre and Post test values of PSQI and level of depression on GDS were analysed using Wilcoxon Signed Rank Test and results obtained.

\section{DISCUSSION}

This experimental study designed showed that CBE can prove effective in improving sleep problems and depression in Institutionalised elderly. The study population recruited were mainly frail elderly, mean age 75.67 years. Since the study population were frail elderly, relative sedentary population having co morbidities, structured CBE was planned to improve sleep problems and depression in elderly. The given CBE were safe and effective as participants showed good adherence to the study programme. No injuries were reported and there were nodrop outs. Previous studies have also proved CBE to be safe and effective for frail elderly.

Effects of CBE to improve sleep quality: In the present study there was improvement in all the components except sleep duration and sleep disturbances of PSQI. Though all the participants were complaining of problems related to sleep, none of them was taking sleep medications.

The possible mechanism explaining improvement of sleep quality with given exercises could be due to following reasons:

1. Thermoregulation - Exercises given causes increase in body temperature, which can activate heat loss. Sleep onset is triggered by decline in body temperature which is mediated by increased blood flow to the skin [9].

2. Exercises may also improve sleep by body restoration and energy conservation - high catabolic activity during wake will be favoured by anabolic activity during sleep [10].

3. Chronic insomnia is associated with low level of serotonin level. Exercises given may regulate regulatory mechanism that may increase serotonin level [9].

Effects of CBE to improve depression on GDS The depression score showed improvement on 
GDS. This could be due to:

1. Exercises help in releasing endorphins, feel good harmon, which help in improving mood

2. Laughter acts as a moderator of stress for depressive symptoms.Laughter exercises have contributed to reduce stress and causing relaxation of muscle group, reducing skeletal muscle tone [11].

3. Since most people with depression report sleep disturbances, regulation of sleep through exercises can help in reducing depression.

Limitations: Small sample size was selected for study programme.There was no control group as it was difficult to have frail and very frail elderly who were ready to participate in study programme.

Clinical Implication: Though prevalence of Insomnia and depression increase with advancing age, they should not be refereed as expected changes due to aging.

These problems coexist and go undetected so screening of these problems should be considered by physiotherapist while planning fall prevention programme.

Simple gradual CBE should be considered as starting programme for sedentary older people as it is cost effective, can be done in any community setting, does not require any equipment to improve sleep quality and depression .

\section{CONCLUSION}

CBE can be used as simple and effective way to improve self reported sleep problems and depression in elderly.

Compliance to CBE is generally better than that of standing exercises especially among frail elderly, with low level of function and co morbidity.

\section{ABBREVIATIONS}

PSQI -Pittsburg Sleep Quality Index,

GDS - Geriatric depression Scale,

CBE -Chair Based Exercises.

\section{ACKNOWLEDGEMENTS}

We sincerely thank to all our elderly study participants for being active participants of the study programme, stasticians, the authorities and caretakers at the old age home who made our study possible.

\section{Conflicts of interest: None}

\section{REFERENCES}

[1]. Diagnostic Classification Steering Committee TMJC.International classification of sleep disorders. $3^{\text {rd }}$ edition. Rochester (NY);American Academy of Sleep Medicine:2014.

[2]. Vitiello M V,Moe K E,PrinzPN.Sleep complaints cosegregate with illness in older adults;clinical research informed by and informing epidemiological studies of sleep.JPsychosom Res.2002;53:555-559.

[3]. Juan Carlos Rodriguez,M D Joseph M.Dzierzewski, CathyA.Alessi - Sleep problems in the Elderly Medical Clinics of North America.2015Mar;99(2):431439.

[4]. Miranda Varrase et al.Curr Sleep Medicine Rep.Exercise and sleep in community dwelling older adults.2015;1:232-240.

[5]. Bloom H G et al.J Am GeriatrSoc.Evidence based recommendations for the assessment and management of sleep disorders in older person.J Am Geriatr Soc. 2009 May;57(5):761-789.

[6]. Morin C M,LeBlanc M,BelangerL, IversH, MeretteC, SavardJ.Prevalance of Insomnia and its treatment in Canada.Can J Psychiatry.2011;56(9):540-8.

[7]. Jaussent IBouyerJ,AncelinML,AkbaralayT,Peresk, Ritchie $\mathrm{K}$ et al. Insomnia and daytime sleepiness are the risk factors for depressive symptoms in the elderly.Sleep 2011;34(8):1103-10.

[8]. Robinson KR,Leighton Logan $P$ etal.Developing the Principles of Chair Based Exercises for older people :a modified Delphi Study.BMC Geriatr.2014 May; 19:14:65.

[9]. BuysseDJ,et al . The Pittsburg Sleep Quality Index: a new instrument for psychiatric practice and research.Psychiatry Res.1989

[10]. Esther Heerama.Geriatric Depression Scale -Long and Short form content and scoring.Very well mind.com/geriatric depression scale -98621.

[11]. Passos G S,Poyares D L,Santana M G,TufikS,Mello M T.Is exercise an alternative treatment for chronic Insomnia?Clinics(Sau Paulo).2012;67(6);653-60.

[12]. Montgomery P,Dennis J.Physical exercises for sleep problems in adults aged sixty plus.Cochrane database Syst Rev.2002;4.

[13]. PaskindJ.Effects of laughter on muscle tone .Arch Neurol Psychiatry 1932;28:623-628.

How to cite this article: Sheetal Aurangabadkar, Medha Deo. EFFICACY OF CHAIR BASED EXERCISES TO IMPROVE SELF REPORTED SLEEP PROBLEMS AND DEPRESSION AMONG INSTITUTIONALISED ELDERLY. Int J Physiother Res 2020;8(1):3359-3365. DOI: 10.16965/ ijpr.2019.202 